\title{
Correction to: Retinal Degenerative Diseases
}

Catherine Bowes Rickman, Christian Grimm, Robert E. Anderson, John D. Ash, Matthew M. LaVail, and Joe G. Hollyfield

\section{Correction to:}

C. Bowes Rickman et al. (eds.), Retinal Degenerative Diseases, Advances in Experimental Medicine and Biology 1185, https://doi.org/10.1007/978-3-030-27378-1

\section{Chapter 8:}

The title of the chapter is "Melatonin as the Possible Link Between Age-Related Retinal Degeneration and the Disrupted Circadian Rhythm in Elderly" where degeneration was incorrectly published as regeneration. Now this has been corrected to degeneration.

\section{Chapter 60:}

The acknowledgement section was missed and this has been added to the chapter.

The updated online version of these chapters can be found at https://doi.org/10.1007/978-3-030-27378-1_8 https://doi.org/10.1007/978-3-030-27378-1_60 